\title{
ПЛОЩАДНОЕ РАСПРЕДЕЛЕНИЕ РАСПЫЛЕННОГО ВЕЩЕСТВА МЕТЕОРИТА КААЛИ
}

Исследования по распределению распыленного метеоритного вещества в непосредственной окрестности мелких метеоритных кратеров Каали были начаты в 1975 г. Поводом этому послужили находки мелких осколков метеорита вне контура малых кратеров (Aaloe, 1958). Систематическое изучение проб грунта в окружности кратера № 4 подтвердило перспективность таких исследований. На основе этих работ выявлены главные закономерности распределения распыленного метеоритного вещества и разработана предварительная их классификация (Аалоэ, Тийрмаа, 1981; Аалоэ, Тийрмаа, 1982a). Позднее эта классификация несколько усовершенствована с учетом четкого разграничения в ней общепризнанных терминов «метеорная» и «метеоритная» пыль (Tiirmaa, 1984).

По этой классификации в районе мелких кратеров Каали наибольшим распространением пользуется метеорная пыль. Метеоритная пыль, особенно метеоритные осколки приурочены только к близким расстояниям от кратеров.

В общем распределение мелкодисперсного вещества по площади мелких кратеров коррелирует с проекцией траектория падения метеорита, $\mathbf{6}$ одной стороны, и с условиями взрывного кратерообразования: с испарением и разбрызгиванием метеоритного вещества из кратера, с другой. Корреляция эта не очень отчетлива, но все же ощутима (Аалоэ, Тийрмаa, 1982a; Tiirmaa, 1984). При этом следует отметить, что ни в одном случае вокруг изученных мелких кратеров не удалось наблюдать концентрации метеоритного вещества в определенных радиальных направлениях, что обычно сопровождается в подобных случаях. Частота опробования и характер изученного слоя почвы позволили бы обнаружить лучисто-струевой эффект взрыва. Отсутствие его в Каали трудно объяснимо, возможно, определенное влияние оказали здесь процессы сглаживания в ходе земледельческих работ.

Успехи, достигнутые в изучении зон обрамления мелких кратеров побудили ставить аналогичные исследования и на более обширных площадях вокруг целого кратерного поля Каали. Способствовали этому и геологические особенности территории, в основном распространение на больших площадях выдержанного подстила основной морены, в меньшей степени выходов коренных пород силура, которые надежно задерживали механический вынос метеоритного вещества вниз по профилю. Интенсивное земледелие в этом районе создало в пахотном слое постоянно действующий механизм обогащения низов почвенного профиля тяжелыми частицами, что также могло содействовать результативному сбору сохранившегося материала Каалиской катастрофы.

Использованная методика сбора материала довольно проста: грунтовые пробы весом 4-6 кг отбирались на глубине от 15 до 45 см в основании пахотного слоя непосредственно над поверхностью незатронутой морены. Пробы промывали для удаления гумуса, растительных остатков и глинистого вещества в полевых условиях. Более крупные фракции 
( $>5$ мм) - гальки и обломки пород - отсеивали. После этого пробы подвергали сухой магнитной сепарации, а магнитную фракцию просматривали под бинокуляром и выделяли в ней по морфологическим признакам частицы предполагаемого метеоритного происхождения. Последние взвешивали на аналитических весах и с учетом исходной навески расчитывали концентрацию этих частиц в грунте $\left(г / \mathrm{m}^{3}\right)$.

Естественно, что во всех пробах присутствовал земной магнетит, но в разном количестве и в разных морфологических выражениях, что значительно усложняло идентификацию метеоритного и импактитного материала. Кроме того, необходимо учитывать как естественный фон космической пыли, так и возможность попадания в пробы частиц техногенного железа. Однозначная диагностика метеоритных образований в полученном материале представляла часто сложную задачу и внесла в конечный результат определенную долю условности.

Важным при этом является сохранность метеоритного материала, на которую оказали влияние многие геологические факторы. Ощутимую роль в течение последних 2000 лет сыграл антропогенный фактор: перемешивание различных слоев при обработке земель способствовало аэрации дисперсного метеоритного железа в верхних горизонтах почвы, следовательно, и его окислению, а также гидратации и коррозии гумусовыми веществами. Все это могло привести к значительной потери метеоритного вещества, но, с другой стороны - и к его механическому накоплению в зоне спая почвы с подстилающей мореной. Метеоритный материал мог сноситься с поверхности морены и другими денудационными процессами, в частности в ходе перекрытия о-ва Сааремаа водами разных трансгрессий Балтийского бассейна. Все это делает шансы нахождения непосредственных следов Каалиского метеоритного взрыва весьма сомнительными.

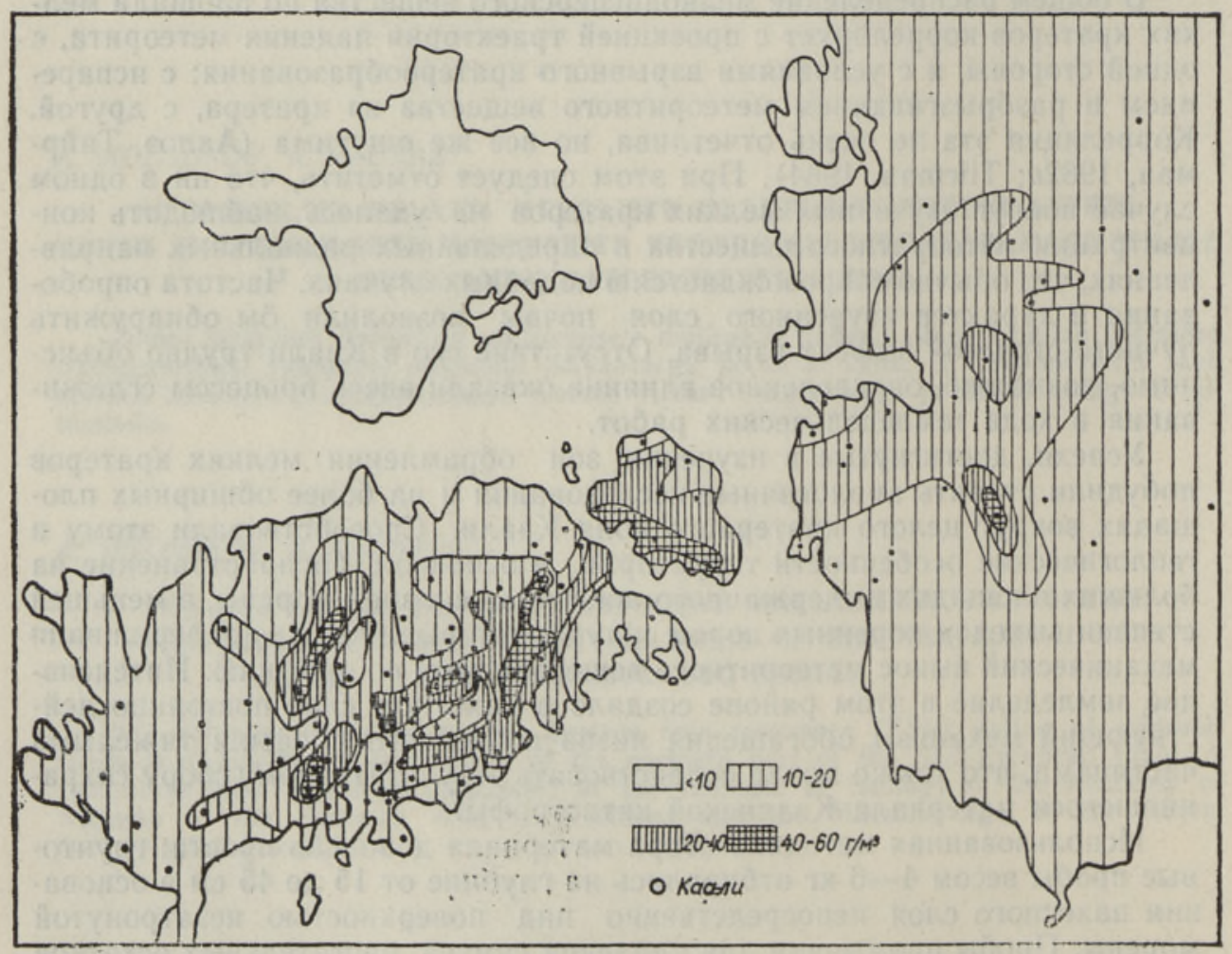

Площадное распределение распыленного вещества метеорита Каали. 
Однако данные по анализу фона предполагаемой космичерской пылй являются все же обнадеживающими (рисунок). Оказывается, что территорию с повышенными концентрациями вещества со всех сторон окаймляет зона, где количество метеоритного материала не превышает $10 \mathrm{r} / \mathrm{m}^{3}$. Зоны с такими низкими содержаниями проб встречаются наряду с зонами повышенного количества сепарированного метеоритного материала и в центральной части изученной площади.

Это дает основание предполагать, что более высокие концентрации определенных нами частиц метеоритного происхождения характеризуют именно те участки территории, которые оказались под влиянием «дождя» распыленного материала метеорита Каали. Такое предположение подтверждается контурами этих полей на рассматриваемой карте вырисовывается отчетливая полоса аномалий вдоль предполагаемого пути падения метеорита (рисунок). Сама структура этой полосы весьма сложна, единость ее прерывается пятнами более низких концентраций, о причинах наличия которых было сказано выше. Однако общее направление полосы концентраций вещества в количестве $>10$ г/м ${ }^{3}$ выдерживается хорошо и обозначает «след» метеорита в направлении его падения.

Наиболее обогащенная зона метеоритного вещества наблюдается в районе Вальяла-Ирусте-Пёйде, отчасти и на юго-западе о-ва Муху. Поэтому можно предполагать разрушение основного тела метеорита Каали именно в этом районе, откуда дальше на запад он двигался уже в виде отдельных метеоритных глыб. С разрушением сопровождалось возникновение больших количеств раскаленного металлического метеоритного вещества, поверхность которого быстро окислялась в магнетитовые пластинки и шарики. В пробах данного района таких частиц около $90-$ $95 \%$.

Две обогащенные зоны наблюдаются и западнее Каали, немного севернее г. Кингисеппа. Можно предположить, что они возникли путем новых порций распыленного метеоритного вещества при ударе метеорита о поверхность Земли. Возможно, именно в этом выражен радиальнолучевой эффект взрыва метеорита.

Вытянутый контур ареала распыленного метеоритного вещества точно совпадает с направлением падения метеорита и по другим данным - по форме ударного следа, по морфологии главного кратера, а также по зоне разрушения пород вокруг главного кратера (Аалоэ, Анд$\mathrm{pa}, 19826)$. Все это позволяет считать, что все случайные техногенные искажения (земледельческое и индустриальное железо и др.) не изменяют принципиальную картину выявленного распределения распыленного вещества Каалиского метеорита, так как их доля остается при достаточной навеске пробы в пределах допустимой ошибки анализа. Исключение составляет только одна аномальная точка южнее Лихула. Она представлена одной единственной пробой, которая не отличается при визуальном осмотре от проб метеоритного вещества.

Следует еще отметить, что найти каких-либо дополнительных критериев для однозначной идентификации распыленного метеоритного вещества в магнетитовой форме нам не удалось. Высокое содержание никеля существенно снижается при окислении, ввиду чего спектральные анализы этих образований мало отличаются от анализов земных магнетитов. Главным критерием служит все же морфология частиц, но и она не лишена большой доли условности. Однако надежность этого признака постепенно увеличивается в направлении кратеров метеорита.

Если выявленная полоса с повышенной концентрацией метеоритоподобного вещества в почвенных пробах действительно относится к Каалискому метеориту, то по данным составленной карты можно провести расчеты исходной массы метеорита. Так, если взять средним содержанием метеоритных частиц в контуре зоны $>10 \mathrm{r} / \mathrm{m}^{3}$ около $20 \mathrm{r} / \mathrm{m}^{3}$, то при учете 


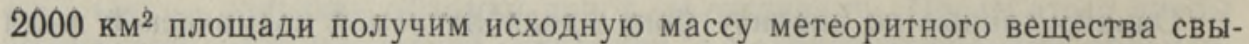
ше 10000 т, что существенно превосходит расчетную массу метеорита по взрывным параметрам кратера в Каали (Бронштэн, Станюкович, 1963). Это позволяет заключить, что бо́льшая часть массы метеорита Каали разбрызгивалась над траекторией его падения и не достигла земной поверхности в виде крупных тел. Вслед за падением метеорита здесь долго оседали дисперсные частицы металла и магнетита, в распределении которых существенную роль мог играть ветер. Совпадение ареала распространения вещества с направлением преобладающих в этом районе ветров заставляет учитывать и такую возможность.

\section{Л И Т Е РА Т Р А}

Аалоэ А., Тийрмаа $P$. Распыленное метеоритное и импактитное вещество на кратерном поле Каали. - Изв. АН ЭССР. Геол., 1981, 30, № 1, 20-27.

Аалоэ А. О., Тийрмаа Р. T. Метеоритное вещество в мелких кратерах Каали и в их окрестности. - Метеоритика, 1982a, № 41, 120-125.

Аалоэ A., Андра X., Андра В. Направление падения метеоритного дождя Каали по геофнзическим данным. - Изв. АН ЭССР. Геол., 1982б, 31, № 2, 56-61.

Бронитэн В. А., Станюкович $К$. П. О кратерообразующих метеоритах. - Тр. Ин-та геол. АН ЭССР, 1963, XI, 73-83.

Aaloe, A. Kaalijärve meteoriidikraatri nr. 5 uurimisest 1955. aastal. - ENSV TA Geol. Inst. Uurim., 1958, II, 105-117.

Tïrmaa, $R$. Kaali meteoriidiainet otsimas. - Eesti Loodus, 1984, N 9, 571-576.

Ннститут геологии

Академии наук Эстонской ССР
Поступила в редакцию 1/VIII 1986

\section{Reet TIIRMAA}

\section{KAALI METEORIIDI PIHUSTATUD AINE LEVIKUST}

On selgitatud pihustatud meteoriitse aine leviku põhilised iseärasused Kaali meteoriidikraatrite väljal ja selle ümbruses Saaremaal, Muhus ja Lääne-Eestis.

$30-45 \mathrm{~cm}$ sügavuselt vōetud 4-6-kilosed pinnaseproovid pesti huumusest, taimejäänustest ja savist puhtaks, sōeluti 5 -millimeetrisel sōelal, separeeriti magnetiga ning eraldati magnetilisest fraktsioonist binokulaari abil oletatavad meteoriitse päritoluga osakesed, mis seejärel kaaluti. Nii saadi andmed meteoriitse aine iseloomu ning kontsentratsiooni kohta uuritavas pinnasekihis.

Pihustatud meteoriitse aine levikukaart on rahutu ja võrdlemisi keerukateks väljadeks jaotunud, kuid eristab selgesti kõrgenenud sisaldusega vööndi oletatava meteoriidi langemise trajektoori projektsioonil. See vöönd on oodatust tunduvalt suurema pindalaga, mis viitab Kaali meteoriidi algmassi hajuvusele väga suurel territooriumil.

Kõrgenenud meteoriitse aine sisaldusega alasid vōib leida ka Kaalist lääne pool. Nende teke seletub kõige tõenäolisemalt materjali radiaalse laialipaiskumisega meteoriidi löögil maapinnale.

\section{Reet TIIRMAA}

\section{DISTRIBUTION OF PULVERIZED METEORITIC MATTER IN THE KAALI CRATER FIELD}

The main peculiarities of the distribution of pulverized meteoritic matter were investigated in the Kaali meteorite craters field and in its surroundings in Saaremaa, Muhu and West Estonia.

Samples of $4-6$ kilograms in weight, taken in a depth of $30-45 \mathrm{~cm}$ were washed to clean the matter from humus, plant remains and clay. After the sieving (diameter $5 \mathrm{~mm})$ and magnetic separation, the meteoritic particles were collected under binocular and weighed. The character of meteoritic matter and its concentration in the soil were determined.

The map of pulverized meteorite matter (the Figure) shows a mostly uneven distribution with complicated fields, but after all, the zone of higher concentration is distinguishable, pointing clearly to the projection of the supposed fall trajectory of the meteorite. This zone seems to have a far extensive distribution than was presumed. It can be explained by dissipation of the initial meteoritic matter on a large territory.

Areas with the hightened content of meteoritic matter were established also westwards of Kaali. Most probably their origin can be explained by the radial flunging of the matter after the meteoritic impact. 